ISSN: 1130-2887 - eISSN: 2340-4396

DOI: https://doi.org/10.14201/alh.27259

\title{
¿FUE LA CRISIS DE LAS MALVINAS UNA GUERRA DE DISTRACCIÓN? UNA REINTERPRETACIÓN DEL DECLIVE ARGENTINO A TRAVÉS DE LA TEORÍA PROSPECTIVA Was the Malvinas/Falklands a Diversionary War? A Prospect-Theory
} Reinterpretation of Argentina's Decline

Luis L. SCHENONI (1) luis.schenoni@ucl.ac.uk ${ }^{1}$

Sean BRANIFF (10) sean.braniff@au.af.edu ${ }^{2}$

Jorge BATTAGLINO (1) jbattaglino@utdt.edu ${ }^{3}$

${ }^{1}$ University College London

${ }^{2}$ United States Air War College

${ }^{3}$ Universidad Torcuato Di Tella

Envío: 2021-09-15

Aceptado: 2021-11-20

First View:

Publicación: 2021-12-31

RESUMEN: ¿Cómo se explica la Guerra de Malvinas? En este artículo revisitamos este episodio a través de un análisis contrafáctico utilizando nueva evidencia documental. Estas fuentes ponen en duda la tesis de la guerra de distracción y la tesis del error de cálculo. La evidencia sugiere que dinámicas de poder de largo plazo y sesgos psicológicos afectando a los miembros de la Junta militar argentina explican de mejor manera las decisiones que llevaron a la guerra.

Palabras clave: Malvinas; teoría prospectiva; análisis contrafáctico; guerra

ABSTRACT: How do we explain the Falklands War? In this article we revisit this episode through a counterfactual analysis using recently declassified documents. These sources cast additional doubt over the diversionary war and miscalculation theses. The evidence suggest that long-term power dynamics and psychological biases affecting the members of the Argentine military Junta better explain the decisions that led to the war.

Keywords: Malvinas/Falklands; prospect theory; counterfactual analysis; war 


\section{INTRODUCCIÓN ${ }^{1}$}

Las dos narrativas más prominentes sobre las causas de la guerra de las Malvinas están basadas en factores domésticos. La primera, la llamada diversionary war thesis (tesis de la guerra de distracción), argumenta que la ocupación argentina de las islas fue el último recurso de un régimen militar impugnado por la opinión pública. De acuerdo con esta lógica, la impopularidad local llevó a la Junta Militar a buscar un efecto de rally 'round the flag (unión en torno a la bandera) y la ocupación de las Malvinas cumplió esta función.

La segunda narrativa, la tesis de miscalculation (error de cálculo), argumenta que el régimen militar pensó que Gran Bretaña no respondería -o lo haría de manera más limitada-a la acción argentina en las islas, y que los Estados Unidos intervendrían para evitar una guerra. Los defensores de esta tesis argumentan que las decisiones tomadas desde Buenos Aires fueron un claro ejemplo de la dificultad de navegar en la niebla de las crisis internacionales y que, con información exacta la ocupación no se hubiera producido.

Estas dos narrativas han explicado la guerra de 1982 hasta hoy en día, pero documentos desclasificados en 2012, incluidas declaraciones de líderes militares argentinos involucrados en la decisión de ocupar las Malvinas, contradicen directamente la sabiduría convencional. Revisar este caso se vuelve imperativo, ya que la guerra de las Malvinas «es el caso arquetípico de guerra de distracción» (Oakes, 2006, p. 432) ${ }^{2}$. Contribuyendo también a la perenne esperanza de vida de estas tesis, explicaciones alternativas no han logrado desafiarlas.

En este artículo, ofrecemos uno de esos argumentos alternativos y lo contrastamos con la tesis de guerra de distracción, la tesis de error de cálculo y otros argumentos existentes. Sostenemos que las raíces de la decisión de la Junta Militar no se encuentran únicamente en factores internos, sino que tienen orígenes sistémicos y componentes a nivel individual. En breve, el declive relativo de Argentina llevó a la proliferación de un marco psicológico negativo (llamado marco de pérdida en teoría prospectiva) entre tomadores de decisiones, lo que explica una larga serie de acciones ofensivas y risk-acceptant (propensas al riesgo) con el objetivo de restaurar la posición del país en la región. Es este contexto de toma de decisiones el que explica, en última instancia, la ocupación de las islas Malvinas.

La línea que va del declive regional a la guerra no puede trazarse sin dos puntos adicionales. El primero es el papel del territorio perdido. Los argentinos estaban convencidos de

1. Este manuscrito se benefició considerablemente de presentaciones en el Congreso de la Sociedad Argentina de Análisis Político (SAAP) el 6 de agosto de 2017 y del Taller de Relaciones Internacionales de la Universidad de Notre Dame del 13 de marzo de 2018. Benjamín Denison, Carlos Escudé, Rosendo Fraga, Eugene Gholz, Ignacio Labaqui, Diego Leiva, Magdalena Lisinska, Dawisson Belem Lopes, Andrés Malamud, Fernando Mourón, Joseph Parent, Kimberly Peh Zi En, Francisco Santibáñez y Andrés Villar ofrecieron valiosos comentarios. Los autores estamos especialmente en deuda con Gary Goertz y James Mahoney por su orientación metodológica y con el Instituto Kellogg de Estudios Internacionales por apoyar la investigación de archivos en Buenos Aires y Londres durante 2018 y 2019, así como los derechos de reimpresión de este artículo, previamemente publicado como «Was the Malvinas/Falklands a Diversionary War? A Prospect Theory Reinterpretation of Argentina's Decline». Security Studies, 29(1), 34-63, https://doi.org/10.1080/096 36412.2020.1693618. Las opiniones expresadas en este artículo son exclusivas de los autores.

2. Esta y todas las traducciones de este artículo fueron realizadas por los autores. 
que habían sufrido una pérdida tangible y, por lo tanto, no lograron normalizar su percepción de sus límites territoriales. De esta manera, las Malvinas se convirtieron en uno de los pocos puntos focales en los esfuerzos del país para recuperar pérdidas en un contexto de declive regional. El segundo punto radica en la estructura de toma de decisiones del régimen: la Junta militar estaba aislada de las instituciones estatales (como agencias de inteligencia y ministerios civiles) que podrían haber servido como mecanismos de desubjetivación. Sin este aporte, el pequeño grupo de élites militares que gobernaban el país fue más propenso a aceptar grandes riesgos, un patrón típico en individuos que han sufrido pérdidas y no las han normalizado.

Esta explicación se ajusta mejor a la evidencia recientemente desclasificada sobre las causas y el desarrollo de la guerra. La Comisión para el Análisis y Evaluación de Responsabilidades en el Conflicto del Atlántico Sur -también conocida como Comisión Rattenbachprodujo un informe que se filtró a la prensa a finales de 1983. Sin embargo, la desclasificación de miles de documentos utilizados para producir el informe se produjo solo después de un decreto presidencial de 2012. Estos documentos comprenden todas las directivas oficiales expedidas durante el período que condujo a la guerra y cientos de entrevistas con funcionarios estatales de alto rango, incluidas las declaraciones de los tres miembros de la Junta, los oficiales militares que planearon la operación, ministerios, diplomáticos y otros. Las declaraciones se registraron dentro de un período de un año después de la guerra, bajo secreto y juramento, y fueron trianguladas por los investigadores, proporcionando pruebas frescas y fiables. Más aún, el teniente general Benjamín Rattenbach, presidente de la comisión, preguntó directamente si la guerra tenía como objetivo distraer a la opinión pública local (diversionary war), en qué medida existieron errores de cálculo (miscalculation) y otras hipótesis que ya circulaban en ese momento. Estas declaraciones recientemente desclasificadas proporcionan evidencia crítica para evaluar la mentalidad de los tomadores de decisiones, pero aún no se han incorporado al debate de este tema en el marco de la ciencia política ${ }^{3}$.

Reevaluar la política exterior de los militares argentinos nos ayuda a comprender el tipo de comportamiento que los líderes de potencias en declive podrían tener bajo presiones similares. Las teorías de las relaciones internacionales que abordan los efectos de los cambios de poder en la guerra interestatal han propuesto que los Estados en declive son más propensos a la guerra en promedio, pero la literatura sigue siendo difusa al explicar por qué los líderes de estos Estados preferirían la incertidumbre de la guerra a una adaptación pacífica. Este artículo identifica las condiciones bajo las cuales el declive relativo puede conducir a la guerra. Proponemos que el comportamiento de aceptación del riesgo de la política exterior en Estados en declive, aunque impredecible en un marco de utilidad esperada, es anticipado por un paradigma alternativo en psicología cognitiva: la teoría prospectiva. Si los líderes de los Estados en declive piensan y se comportan de la manera que predice la teoría prospectiva -como ya se ha demostrado a través de estudios experimentales a individuos que sufren pérdidas- entonces la guerra puede convertirse en una estrategia razonable para ellos.

Para defender nuestro argumento, seguimos esta introducción con tres secciones sustantivas. Comenzamos proponiendo que la interpretación de la política exterior de Estados en

3. El material de archivo citado a lo largo de este artículo está disponible en línea en: https://www. casarosada.gob.ar/informacion / archivo / 25773-informe-rattenbach. 
declive debería incorporar nociones de teoría prospectiva. Luego discutimos cómo las pérdidas tangibles percibidas (por ejemplo, pérdidas territoriales) proporcionan un punto focal contra el cual los líderes miden su posición, y cómo las expectativas de comportamiento de la teoría prospectiva pueden agregarse al nivel estatal cuando el marco institucional aísla a los tomadores de decisiones. La siguiente sección pasa al caso bajo consideración. Primero, utilizamos el análisis contrafáctico para descartar las narrativas comunes que explican por qué la Junta argentina atacó las Malvinas. Finalmente, exponemos nuestro argumento en detalle, explicitando sus implicaciones observacionales y proporcionando evidencia sistemática a su favor. Concluimos el artículo con implicaciones para la teoría y para la investigación futura.

\section{LA TENDENCIA AL RIESGO EN ESTADOS DECLINANTES}

La literatura sobre transiciones de poder asegura que la guerra es más propensa en contextos de cambio de poder relativo entre Estados. Organski y Kugler (1980) concluyen sucintamente que las «diferencias en las tasas de crecimiento son el problema fundamental que hace que todo el sistema se deslice casi irremediablemente hacia la guerra», (p. 61). También para Gilpin (1981) en estos contextos «el desequilibrio reemplaza al equilibrio, y el mundo avanza hacia un nuevo ciclo de conflicto hegemónico» (p. 210). Más recientemente, los autores interesados en estas dinámicas se han enfocado en el efecto del declive, más específicamente. Dale Copeland (2000, p. 1) concluye que el miedo al futuro de las potencias en declive es la «causa común» de las grandes guerras «a lo largo de los milenios». Del mismo modo, Graham (2017) cita el miedo a los retadores en los Estados que están en relativo declive como una de las principales causas de guerra (Goddard, 2018). Estas dinámicas afectan también a Estados pequeños (Lemke, 2002; Schenoni, 2018).

A lo largo de esta literatura, el declive se define generalmente como una disminución en las capacidades materiales de un Estado en el marco de una clasificación ordinal entre sus competidores durante un período determinado (MacDonald y Parent, 2018; Itzkowitz, 2018). Sin embargo, el declive material relativo está intrínsecamente entrelazado con preocupaciones más amplias sobre estatus (Wolf, 2011; Onea, 2014). Aunque no existe ninguna jerarquía en la política internacional, los Estados buscan el mayor grado de autonomía y apalancamiento dentro de su esfera de influencia (Wohlfort et al., 2018) y, por lo tanto, son «reacios a renunciar a su influencia y control sobre las instituciones, el territorio y los mercados» (Thompson, 2014, p. 244). Recuperar estatus o prestigio podría ser una justificación suficiente para la guerra (Kirshner, 2000), aunque examinar la dinámica del poder a través de un lente exclusivamente racional puede conducir a varios resultados posibles (Bueno de Mesquita, 1981). Estos resultados pueden variar desde la reducción del gasto y la disminución de la gran ambición estratégica hasta la expansión estratégica (MacDonald y Parent, 2018). Por lo tanto, los mecanismos que conectan el declive con un comportamiento agresivo no están claros (Levy, 1987).

De acuerdo con una amplia literatura en psicología cognitiva, sostenemos que, aunque el supuesto de racionalidad puede ser una buena guía para el comportamiento del Estado en tiempos «normales», la teoría de la utilidad esperada no funciona bien en contextos donde están involucradas grandes pérdidas y un gran riesgo (Levy, 1997, pp. 87-112) -precisamente 
las condiciones que enfrentan las élites de los Estados en declive-. Si los líderes de un Estado en declive perciben pérdidas tangibles, es posible que pasen por alto el razonamiento de utilidad esperada. Estos sesgos pueden amplificarse si el proceso de toma de decisiones está blindado de mecanismos institucionales que podrían corregirlo. En general, tal situación podría conducir al tipo de comportamiento predicho por la teoría prospectiva sobre la aceptación del riesgo (Kahneman y Tversky, 1979). Esta teoría psicológica se ajusta particularmente bien a metáforas emocionales en textos clásicos sobre política internacional (pensemos en la reflexión de Tucídides sobre el temor que una Atenas en ascenso generó en Esparta) ${ }^{4}$ y debería considerarse seriamente como una alternativa al supuesto de racionalidad.

La teoría prospectiva, en contraste con la teoría de la utilidad esperada, ofrece una explicación positiva en lugar de una explicación normativa del comportamiento humano en condiciones de riesgo. Se centra en los procesos cognitivos reales y sus corolarios en lugar de ficciones útiles (Glaser, 2010; MacDonald, 2003) han sido probados experimentalmente. Cuando razonan en forma prospectiva, los actores ven los resultados de sus políticas no en términos de su utilidad final, sino como pérdidas en relación con un punto de referencia. Este marco de pérdidas ayuda a organizar información y es una guía de comportamiento (Kahneman y Tversky, 1979). A esto debemos sumar el hecho de que los humanos renormalizamos puntos de referencia rápidamente después de haber recibido ganancias, pero somos mucho más lentos para normalizar pérdidas, lo que nos hace propensos a asumir riesgos por más tiempo en esos contextos. La metáfora más intuitiva para entender este comportamiento es la de un casino. Todos hemos experimentado el contraste entre la tranquilidad de apostar mientras estamos ganando y el impulso casi patológico a seguir apostando para recuperar lo perdido, aun cuando la probabilidad de recuperar lo perdido es ínfima. La teoría prospectiva captura este impulso a asumir más y más riesgos en contextos de pérdida, el cual está profundamente arraigado en la genética humana.

La teoría prospectiva tiene algunas implicaciones importantes para el comportamiento de élites en Estados en declive. Entre las seis implicaciones de la teoría prospectiva enumeradas por Levy (1997) para la literatura de Relaciones Internacionales (RRII) en general, encontramos tres especialmente importantes para el alcance de nuestro estudio: (1) los líderes estatales asumen más riesgos para mantener su estatus; (2) tienden a no adaptarse al nuevo statu quo después de sufrir pérdidas (Jervis, 1992); y (3) porque esta adaptación es lenta, los costos irrecuperables (también llamados costos hundidos) a menudo influyen en la toma de decisiones futuras (Taliaferro, 2004). Es a través de esta lógica que una pérdida anterior, especialmente una pérdida que no es abstracta sino tangible y concreta, como el territorio, puede convertirse en un punto de referencia para los líderes estatales y un punto focal para tratar de revertir el declive.

El precedente histórico de los límites territoriales, por lo tanto, cobra gran importancia en las mentes de los tomadores de decisiones que enfrentan estas circunstancias (Abramson y

4. Graham Allison, Dale C. Copeland y otros como John J. Mearsheimer se basan en gran medida en la noción de miedo, un estado mental particular que podría restringir el comportamiento racional. Los estudios sobre psicología cognitiva han determinado que la toma de decisiones rara vez es racional cuando este tipo de ansiedad es un factor que impulsa el comportamiento (cf. McDermot, 2004). 
Carter, 2016). Las élites de los Estados en declive que enfrentan pérdidas tangibles están, por definición, en una situación propensa a aceptar mayores riesgos. Esto refuerza nuestra intuición de que los estudios sobre la toma de decisiones de política exterior deben considerar la psicología de las élites que toman esas decisiones (Jervis, 2017). Los individuos «conservan recursos cognitivos en la búsqueda y procesamiento de información» (Jervis, 2017, p. 34) y, por lo tanto, los factores que afectan su pensamiento son absolutamente claves (McDermott, 1998).

Sin embargo, ¿cómo se pueden agregar las implicaciones a nivel individual de la teoría prospectiva al nivel estatal? (Levy, 1997, p. 102). Una forma de abordar este problema sería simplemente abstraer las decisiones de las élites en cuanto a la política exterior en las acciones del Estado ${ }^{5}$; de hecho, atribuir cualidades individuales al Estado tiene una larga historia en la literatura sobre relaciones internacionales (Escudé, 1994). Sin embargo, en la vasta mayoría de los casos, el comportamiento del Estado es una agregación de comportamientos individuales. Debido a esto, las reglas de agregación que tienen lugar en cualquier sistema político son claves para determinar el impacto de los factores psicológicos.

Las élites ejecutivas de la política exterior rara vez operan de forma aislada y otras instituciones (por ejemplo, legislaturas) o «burocracias de política exterior, principalmente servicios de inteligencia», pueden contrarrestar sus sesgos cognitivos naturales (Jervis, 2017, p. 56). No es que el secretismo y el aislamiento ejecutivo no puedan ocurrir en las democracias (Rosato, 2003), ni que las robustas burocracias de política exterior presenten información imparcial (Jervis, 2010); sin embargo, en estos entornos es más probable que los tomadores de decisiones «consideren explicaciones alternativas basadas en datos y piensen más detenidamente en las creencias e imágenes que subyacen a sus preferencias políticas» (Jervis 2017, p. 416). Debido a esto, argumentamos que es más probable que las implicaciones de la teoría prospectiva afecten el comportamiento del Estado en el entorno de toma de decisiones en los que las élites de la política exterior están protegidas de las instituciones estatales que típicamente influyen en la política exterior, como ocurrió con la Junta Militar argentina ${ }^{6}$. En otras palabras, es más probable que un marco de pérdida se apodere de toma de decisiones cuando el pensamiento negativo toma lugar en un grupo pequeño y aislado de toma de decisiones ${ }^{7}$.

5. En este sentido, no es más problemático agregar la teoría prospectiva al comportamiento estatal que argumentar que un Estado «piensa» racionalmente. Jeffrey W. Taliaferro destaca este punto, entre otros, en su estudio que utiliza la teoría de prospectos para analizar intervenciones periféricas de grandes potencias. «Teoría de la utilidad esperada y teoría de la perspectiva», señala, "por sí mismas, no generan predicciones sustantivas sobre los resultados internacionales o el exterior comportamiento político de los estados. En cambio, uno debe incrustar conceptos de estas teorías de decisión en teorías específicas de la política exterior y la política internacional» (Taliaferro, 2004, p. 32).

6. Al señalar un papel en nuestro argumento a favor del aislamiento de la Junta de las influencias que pueden haber ayudado a desviarla de atajos cognitivos, no queremos dar a entender que las teorías basadas en la teoría prospectiva no tengan ningún papel en analizar las decisiones de política exterior de otros tipos de regímenes. De hecho, los académicos han empleado la teoría prospectiva en estudios de una variedad de regímenes.

7. Existe evidencia de que la teoría prospectiva se aplica no solo a personas que toman decisiones de forma aislada, sino también en dinámicas de grupo. 


\section{FIGURA 1. MECANISMOS CAUSALES}

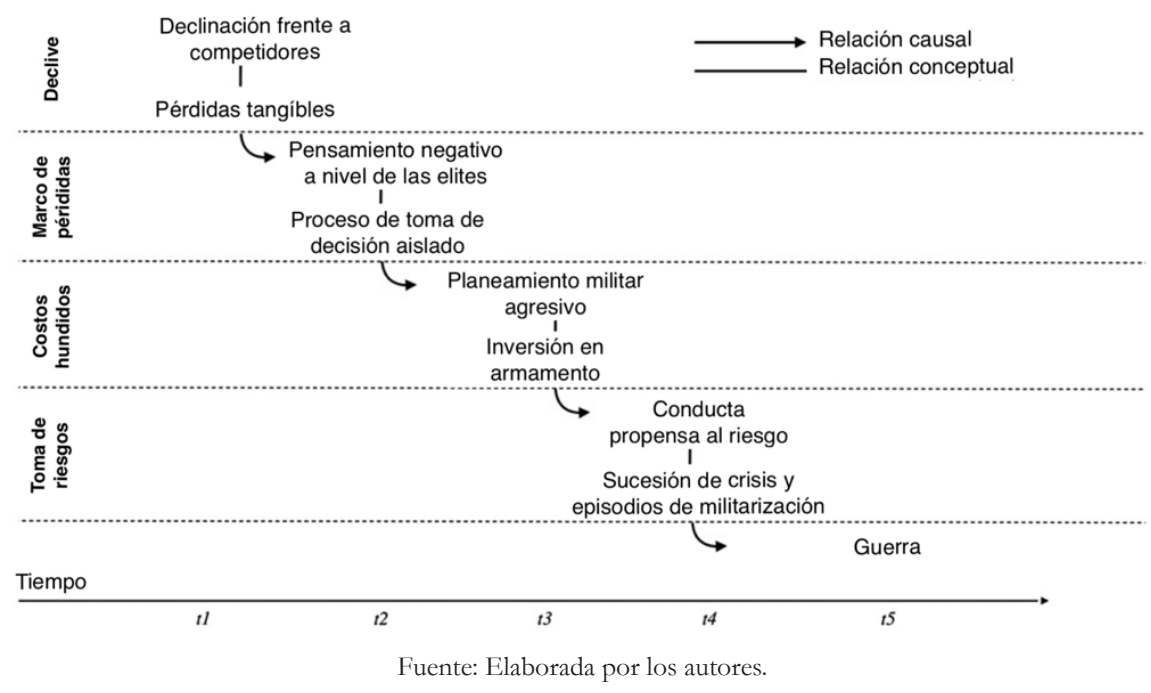

Nuestro mecanismo causal básico propuesto se muestra en la Figura 1. Esta figura se divide en cinco capas o pasos horizontales. En un primer paso, la caída de un Estado en el rango ordinal entre los competidores debe combinarse con una pérdida tangible -por ejemplo, territorial-para inducir a las élites a pensar que están en el reino de las pérdidas. En un segundo paso, las percepciones negativas de la élite deben combinarse con una estructura de toma de decisiones pequeña y aislada para que este marco de pérdida pueda apoderarse del Estado. En un tercer paso, una planificación agresiva y una inversión militar se combinan, colocando al Estado en una conducta de dependencia de la trayectoria que se refuerza a sí misma por la percepción de los costos irrecuperables. Esto lleva a un comportamiento de aceptación del riesgo en un cuarto paso, que está destinado a producir resultados subóptimos: crisis diplomáticas, disputas militares y, en casos extremos, la guerra como quinto y último paso.

Cuando afirmamos que estos pasos son necesarios, no queremos decir que cada uno sea necesario para todas las guerras, ni queremos decir que sean necesarios en su relación individual entre ellos -por ejemplo, que la propensión al riesgo no puede suceder en ausencia de un marco de pérdida-. En cambio, argumentamos que cada una de estas condiciones son partes insuficientes pero necesarias de un conjunto mayor de condiciones que es en sí mismo innecesario pero suficiente (INUS) para producir el resultado en nuestro caso. En otras palabras, estos son eslabones necesarios de la cadena que comprende nuestra teoría, que creemos suficiente, pero no necesaria, para explicar las acciones de la Argentina en el caso de las Malvinas.

Nuestra teoría mejora las tesis de la guerra de distracción y el error de cálculo en varios aspectos importantes. La tesis de la guerra de distracción se centra en las causas inmediatas de la invasión del 2 de abril -por ejemplo, una manifestación del 30 de marzo contra el gobierno-, pero no explica la predisposición inicial de la Junta. Por el contrario, la tesis del error de cálculo explica cómo los sesgos en la Junta permitieron la decisión, pero no puede 
explicar su origen o por qué la Junta persistió en su plan inicial cuando sabía que Gran Bretaña respondería. Nuestra teoría aclara las causas inmediatas y provee una visión de largo plazo. También, puede explicar la agresividad de la Junta antes de la guerra en otros contextos y por qué la decisión de invadir se hizo a fines de diciembre de 1981, justo después de que el teniente general Leopoldo F. Galtieri se convirtiera en presidente. Al explicar otros episodios en el Atlántico Sur, nuestra teoría explica las casusas del adelanto de la invasión, inicialmente planificada para el 15 de mayo, al 2 de abril -lo cual se debió al escalamiento inintencionado de otro episodio arriesgado de militarización en el sur de la isla de Georgia-. Finalmente, nuestra teoría proporciona un complemento sistémico necesario a las explicaciones que se basan únicamente en factores internos y los microfundamentos psicológicos que explican el comportamiento individual de los miembros de la Junta.

\section{UN ANÁLISIS CONTRAFÁCTICO DE LA GUERRA DE LAS MALVINAS}

Según la narrativa más aceptada, Argentina libró la guerra de las Malvinas de 1982 para impulsar la legitimidad de una Junta que, a su vez, interpretó mal la probabilidad de que Londres tomara represalias como lo hizo (Lebow, 1983; Hastings y Jenkins, 1984; Moneta, 1984; Levyy Vakili, 1992; Oakes, 2006). Esta narrativa, sin embargo, implica una serie de razonamientos contrafácticos que no han sido analizados minuciosamente . $^{8}$

$\mathrm{El}$ análisis histórico contrafáctico es una estrategia para la inferencia causal que resulta beneficiosa cuando los académicos enfrentan un único evento histórico y desean calcular diferentes explicaciones posibles para un resultado determinado (Fearon, 1991). La mayoría de las narraciones históricas sobre eventos individuales implican causalidad en forma de un conjunto de condiciones necesarias para que se lleve a cabo el evento (Goertz y Levy, 2007). Por ejemplo, decir que una disminución en el apoyo interno a la Junta provocó la ocupación de las Malvinas equivale a decir que la decadente popularidad de los militares argentinos fue una condición necesaria para que ocurriera la guerra, lo que, a su vez, implica el siguiente contrafactual: si el apoyo interno a la Junta bubiera sido alto, los militares no bubieran lanzado el ataque. Una vez que hacemos estos contrafactuales explícitos, las inconsistencias en el argumento se hacen más evidentes y toda la construcción de esta explicación comienza a desmoronarse.

Las hipótesis del error de cálculo y de la guerra de distracción asumen que la guerra de las Malvinas/Falklands no se habría librado si la popularidad de la Junta hubiese sido alta en marzo de 1982 y Galtieri hubiese calculado correctamente el riesgo de una invasión. Nuestra investigación sugiere que estas suposiciones contradicen directamente siete piezas de evidencia clave:

8. Varios autores que se involucraron con la guerra de las Malvinas también escribieron extensamente sobre contrafactuales (Lebow 2000; Levy, 2008). Las Malvinas se presta a un pensamiento contrafactual. Es uno de los eventos más destacados de la historia argentina reciente, fue inesperado, tuvo un impacto profundamente negativo y los responsables de la decisión estuvieron en esos cargos de poder brevemente y por razones fortuitas. 
1) La Junta ya había actuado agresivamente en contextos cuando el apoyo popular al régimen era alto.

2) La Junta había decidido atacar dos o tres meses antes de que su popularidad comenzara a disminuir.

3) La Junta no tenía planes de realizar campañas psicológicas internas para incrementar su popularidad.

4) El Ejército argentino había calculado correctamente que los británicos responderían al ataque.

5) Los militares sabían que Washington apoyaría a Londres el 1 de abril (un día antes de la ocupación).

6) La Junta conocía el tamaño de la flota británica el 3 de abril y, sin embargo, persistió en su plan inicial.

7) Los planes no solo preveían una respuesta británica, sino aún más contingencias (la participación de Chile).

En conjunto, la evidencia sugiere que el impulso para recuperar las islas fue independiente de los disturbios domésticos y los errores de cálculo, y la invasión habría tenido lugar incluso en ausencia de esos dos factores.

La invasión de las Malvinas/Falklands no fue un estallido inesperado de violencia de un ejército argentino por lo demás sereno. Desde mediados de la década de 1970 el gobierno argentino había comenzado a utilizar regularmente la amenaza de invasión como parte de su estrategia diplomática para recuperar la soberanía sobre las islas. A finales de 1975, la tensión entre Argentina y Gran Bretaña había aumentado y, a principios del año siguiente, el presidente argentino celebró algunas reuniones con el canciller y los tres comandantes de las Fuerzas Armadas para analizar opciones armadas (Kinney, 1989; Escudé, 2010). La tensión alcanzó su punto máximo en febrero de 1976 cuando un destructor de la Armada argentina hizo varios disparos a la proa del barco británico Shackleton para que no continuara su curso hacia las Malvinas.

Adicionalmente, luego del golpe militar de marzo de 1976, Argentina comenzó a construir una base científica en las islas Thule, un territorio en disputa con Gran Bretaña, que luego fue ocupado por la Armada argentina. La instalación continuó operando, a pesar de las protestas del Reino Unido. El gobierno argentino informó a los británicos, a fines de 1976, que estaba dispuesto a interceptar y eventualmente hundir a cualquier intruso en las aguas territoriales argentinas alrededor de las Malvinas, una política que se mantuvo en los años siguientes. Posteriormente, la Armada argentina desarrolló y consideró seriamente planes de ocupación de las Malvinas. En su declaración ante la Comisión Rattenbach, el almirante Jorge Isaac Anaya, uno de tres miembros de la Junta, declara que uno de esos planes se desarrolló en 1977, y que su antecesor, el almirante Emilio Eduardo Massera, lo propuso formalmente a su Junta en 1978. A diferencia de 1982, los otros dos miembros votaron en contra (CAERCAS, 1983e).

También en 1978, la Junta tenía la intención de capturar las islas alrededor del cabo de Hornos y las islas en disputa del canal Beagle -que un tribunal británico, actuando como árbitro internacional, había otorgado recientemente a Chile- obligando a Santiago a reconocer la soberanía de Argentina sobre esta última. El 22 de diciembre de 1978, Argentina lanzó la 
Operación Soberanía, que estaba destinada a retomar las islas por la fuerza. Lo más probable es que la operación hubiera ocasionado una guerra a gran escala si no se hubiera suspendido veinte millas náuticas frente a las costas de Chile debido a una fuerte tormenta (Mares, 2001; Villar-Gertner, 2016). En las siguientes horas la divina intervención del Papa como mediador evitó el conflicto, pero la Armada argentina estaba a horas, algunos dicen que minutos, de comenzar una guerra en el Cono Sur.

Los incidentes de las islas Shackleton/Thule, la propuesta de Massera y la Operación Soberanía refutan directamente una afirmación contrafactual central de las tesis de la guerra de distracción y el error de cálculo: que los militares argentinos no habrían librado una guerra en un clima de amplio apoyo interno al régimen y con abundante información. En los tres episodios, los militares argentinos tenían abundante información sobre los despliegues y planes de guerra de sus homólogos chilenos y británicos. A nivel de la opinión pública nacional, la ocupación de las islas Thule tuvo lugar en un contexto de notable apoyo a la Junta. La Operación Soberanía ocurrió solo unos meses después de que la selección argentina de fútbol ganara el Mundial de la FIFA: posiblemente el logro más preciado en la historia deportiva argentina, lo que resultó en aún una mayor legitimación de la Junta. Además, a mediados de 1978 ya se estaba produciendo un aumento de la productividad que conduciría a un impresionante crecimiento anual del 10 por ciento en 1979 y la guerra contra las organizaciones de izquierda ya había terminado. Argentina vivía entonces un período de "paz autoritaria» (Novaro, 2010), una combinación de estabilidad económica, social y política que llevó a un pico de apoyo popular al gobierno. Sin embargo, era internacionalmente agresiva.

Nuestra segunda pieza de evidencia socava aún más la hipótesis de la guerra de distracción: la Junta tomó la decisión formal de invadir las islas el 5 de enero de 1982, tres meses antes de la ocupación, y al menos dos meses antes de que se deteriorara el frente interno. Con este fin, un grupo de trabajo comenzó a reunirse el 12 de enero y formuló el primer documento de planificación -conocido como Directiva Estratégica Nacional 1 (DEMIL 1) que la Junta aprobó más tarde. La directiva instó a «prever el uso del poder militar para la consecución del objetivo político» (DEMIL, 1982, p. 4). La DEMIL establece claramente que «para lograr negociaciones con Gran Bretaña sería necesario utilizar el poder militan» (CAERCAS, 1983a) para «imponer a Gran Bretaña la aceptación de una situación de facto lo que a su vez conduciría al pleno ejercicio de la soberanía argentina en las Islas Malvinas.» Los testimonios de los seis funcionarios involucrados en la planificación -es decir, los tres miembros del grupo de trabajo y los jefes de Marina del Estado Mayor- demuestran que no se trataba de simples planes militares que pudieran descartarse, sino de recomendaciones de política asertivas. Los jefes de Estado Mayor de la Armada, almirantes Carlos Alberto Büsser (Infantería de Marina), Carlos Alfredo García Boll (Aviación Naval) y Gualter Oscar Allara (Flota), confirman la decisión para llevar a cabo la invasión que ocurrió antes, a fines de diciembre de 1981 (CAERCAS, 1983c; 1983d; 1983e).

Esto está en conformidad con la historiografía reciente que afirma que Galtieri concedió los planes de invasión a cambio del apoyo de la Marina a su presidencia, inaugurada el 22 de diciembre de 1981 (García Holgado y Taccone, 2018). Curiosamente, Galtieri no enfrentaba ningún malestar doméstico en ese momento. Por el contrario, estaba disfrutando de un tranquilo período de luna de miel justo antes de sus vacaciones de verano. 
Un tercer dato que contradice el relato de la guerra de distracción se refiere a la falta de preocupación de los militares por los disturbios domésticos o sobre cómo se comunicaría la ocupación al público -aquello que los militares argentinos denominaban entonces «acción psicológica»-. Si el objetivo principal de la guerra era influir en la opinión pública, la Junta debería haber analizado cómo la guerra afectaría el humor de la opinión pública y preparado cuidadosamente una campaña de propaganda. Sin embargo, la actitud de los militares fue de absoluta indiferencia frente a la opinión pública. La Junta incluso previó una reacción negativa y confió en la represión para hacer frente a los disturbios posiblemente producidos durante la guerra ${ }^{9}$. Oficiales que serían clave en la administración del impacto doméstico de la guerra, como el ministro de Economía, Roberto Alemann, supieron de la ocupación después del hecho, en la mañana del 2 de abril (CAERCAS, 1983d). El ministro del Interior, Alfredo Saint Jean, estaba informando a Galtieri sobre sus negociaciones con los sindicatos cuando este lo interrumpió: «Vamos, Saint Jean ¿tienes que venir con este problema precisamente hoy?» (CAERCAS, 1983c). Posteriormente, el presidente confió a Saint Jean que la ocupación sucedería en unas pocas horas, y le pidió que no hiciera nada y preservara el secreto. El secretario de Inteligencia, Carlos Martínez, posiblemente el funcionario en posesión de la mayoría de los medios para organizar la acción psicológica, también supo sobre los planes la noche del desembarco (CAERCAS, 1983c). La falta de planificación de la campaña de comunicación es un tema central en las entrevistas de Rattenbach.

Si bien estos hechos prueban que los contrafactuales que subyacen a la tesis de la guerra de distracción están equivocados, las siguientes pruebas dan un golpe similar a la hipótesis del error de cálculo.

Primero, está claro que Argentina sabía con precisión cuál sería la respuesta británica. Al menos seis informes de Inteligencia entre 1979 y 1981 habían advertido sobre una considerable respuesta militar de Gran Bretaña a un desembarco argentino en las Malvinas. Por ejemplo, un informe de Inteligencia de 1980 argumentó ya entonces que se produciría una guerra con Gran Bretaña si Argentina decidiera ocupar las islas (CAERCAS, 1983a). Además, una evaluación de Inteligencia naval a finales de 1981 sostuvo que Gran Bretaña respondería con fuerza proporcional si las fuerzas argentinas desembarcaban en las islas. La propia DEMIL 1 donde se decide la ocupación considera: «El Reino Unido puede tener una respuesta militar estratégica a la ocupación de las islas» ${ }^{10}$.

De hecho, los tres miembros del grupo de trabajo encargado de producir DEMIL 1 -contralmirante Juan José Lombardo, mayor general Osvaldo García y el brigadier Martín Plessl- advirtieron a sus comandantes en jefe que el plan para la ocupación de las islas también debería incluir un plan para su defensa (CAERCAS, 1983b; 1983c). Todos los funcionarios involucrados en la planificación estaban convencidos de que habría una respuesta

9. Sin ir más lejos, el Ejército argentino había reprimido con éxito una manifestación el 30 de marzo. Debemos recordar que los militares habían sofocado un levantamiento guerrillero en 1976-78 que llegó a rincones distantes del país, que había demostrado la eficacia del Estado argentino en reprimir a su sociedad. Estos hechos y varias declaraciones a la Comisión Rattenbach refutan la tesis según la cual los militares no pudieron recurrir a la represión en marzo de 1982.

10. Ibid., p. 376. 
británica (Luzuriaga, 2013). Además, el 23 de marzo, un día antes de que el Día D se estableciera, el Estado Mayor produjo un documento identificando «seis capacidades diferentes, desde la no reacción hasta la reacción con un importante grupo de trabajo» (CAERCAS, 1983b). En otras palabras, cuando los detalles del desembarco estaban siendo discutidos, la Junta predijo una respuesta británica en cinco de cada seis escenarios, y previó la reacción que efectivamente tuvo lugar -la reacción proporcional británica- como el escenario más probable.

La decisión de la Junta de permanecer en curso de colisión antes de que comenzara el combate también refuta la tesis de error de cálculo. Los militares argentinos no retrocedieron durante el mes entre el despliegue del grupo de tareas británico (3 de abril) y el bombardeo de Puerto Argentino/Port Stanley (1 de mayo). Las autoridades argentinas tenían toda la información relevante antes de que estallaran las hostilidades.

La Junta también sabía que el Reino Unido podía contar con el apoyo de los Estados Unidos desde antes de la ocupación. El 1 de abril, el embajador argentino en Washington, Esteban Takacs, comunicó a su gobierno que el secretario de Estado, Alexander Haig, sabía de la movilización de tropas y declaró que Estados Unidos se pondría del lado de Gran Bretaña en caso de conflicto (CAERCAS, 1983c). Esa misma noche, el presidente Ronald Reagan llamó a Galtieri para hacer este punto aún más explícito. El presidente argentino respondió con firmeza: «Inglaterra debe reconocer nuestra soberanía esta noche» (CAERCAS, 1983e).

En las siguientes semanas, con la flota británica navegando hacia el sur, las autoridades argentinas rechazaron por lo menos cuatro propuestas que hubieran prevenido las hostilidades y un mayor resultado favorable que la derrota militar: el Consejo de Seguridad de las Naciones Unidas con la Resolución 502; la mediación del general Haig; una mediación del presidente peruano Fernando Balaúnde Terry, y otra del secretario general de Naciones Unidas, Javier Pérez de Cuellar ${ }^{11}$. En cambio, la retórica incendiaria de Galtieri condenó las negociaciones. El 10 de abril, cuando llegó Haig con una propuesta, Galtieri salió al balcón de la Casa Rosada (sede del gobierno nacional de Argentina) y dijo públicamente: «iSi quieren venir, que vengan! Presentaremos batalla» (CAERCAS, 1983e).

Finalmente, una última pieza de evidencia sugiere que no hubo error de cálculo antes de la invasión: documentos recientemente desclasificados confirman que la Junta estaba dispuesta a abrir un segundo frente con Chile (Middlebrook, 1987; Gibran, 1998; Holsti, 1996; Camilión, 1999). El escenario de guerra en dos frentes se cataloga como «muy factible» en los documentos de planificación militar estratégica previos a la guerra de las Malvinas. En particular, DEMIL 1 estableció que la potencial reacción militar del Reino Unido sería confrontada sin afectar las capacidades comprometidas con el frente chileno (DEMIL, 1982).

11. Para una explicación de cómo estas propuestas fueron mejores que la derrota militar para los reclamos de Argentina, ver las declaraciones del Embajador Carlos Ortiz de Rozas (CAERCAS, 1983d, p. 578). Ortiz de Rozas fue el embajador argentino en Reino Unido y uno de los diplomáticos argentinos con mayor conocimiento sobre la política británica y el reclamo de las Malvinas. Sin embargo, quedó completamente al margen de las negociaciones después de finales de 1981 y se sorprendió por el aterrizaje como cualquier otra persona. La Junta también había intentado reemplazarlo con el contralmirante Rodolfo Luchetta, un oficial naval cercano a Anaya, en diciembre de 1981. Esto proporciona más indicios de que la decisión de ir a la guerra ya estaba decidida para entonces. 
Esto creó varios problemas al Ejército, como tener que desplegar reclutas -algunos de ellos sin la instrucción o capacitación adecuadas- en lugar de regimientos de montaña experimentados que estaban mejor preparados para las condiciones climáticas en las islas. Luego, en la reunión del Comité Militar el 16 de marzo de 1982 se aprobó un plan de trabajo que anticipaba varios escenarios incluyendo «el más peligroso de todos: la reacción con un grupo de trabajo importante conectado a Chile» (CAERCAS, 1983b). Este exceso de preparación contradice directamente la falta de preparación implícita en la tesis del error de cálculo.

En general, tres declaraciones contrafactuales clave implícitas en la tesis de guerra de distracción y otros tres contrafácticos contenidos en la tesis del error de cálculo son refutados por los hechos tras un escrutinio minucioso. En lenguaje de process tracing (rastreo de procesos), esta sección propuso seis «pruebas de aro», es decir, pruebas que «proponen que un determinado elemento de evidencia dentro de un caso debe estar presente para que una hipótesis sea cierta» (Mahoney, 2015, p. 207). Cuando las implicaciones de una teoría son transparentes, «fallar una prueba de aro es evidencia de peso en contra de una hipótesis» (Mahoney, 2015, p. 208). Dado que la guerra de las Malvinas a menudo se presenta como un caso paradigmático de la tesis de la guerra de distracción, el análisis presentado previamente tiene importantes implicaciones más allá de este caso (Fravel, 2010; Chiozza y Goemans, 2004).

Si las dos explicaciones más importantes de la guerra de las Malvinas no son corroboradas por la evidencia, ¿qué explica este caso? Una historia alternativa propone que el factor fundamental que condujo a la guerra fue la contracción de la brecha de poder entre el Reino Unido y Argentina. Defensores de esta tesis sostienen que la Junta creía acertadamente que tomar las islas por la fuerza era factible, pero perdieron la guerra debido a ciertas patologías organizativas de los militares argentinos (Arquilla y Moyano-Rasmussen, 2001). Esta narrativa hace un mejor trabajo al enfocarse en tendencias estructurales a largo plazo en lugar de meros factores internos, pero se enfrenta a problemas igualmente graves. Si la Junta percibía que estaban reduciendo la brecha, ¿por qué no esperar simplemente a un mayor declive británico? ${ }^{12}$. La evidencia recién desclasificada contradice esta tesis de dos maneras importantes. Primero, los testimonios sugieren que el despliegue de más barcos británicos hacia el Atlántico Sur fue el detonante inmediato de la decisión de invadir el 2 de abril, sugiriendo que, para la Junta, la ventana de la oportunidad se estaba achicando y no ensanchando. En segundo lugar, ni un solo oficial que testificó a la Comisión Rattenbach mencionó que la victoria contra el Reino Unido era posible. Galtieri pensó que las islas podrían ser «defendidas por tiempo limitado» (CAERCAS, 1983e); Anaya pensó que «nunca podrían ganar una guerra contra Gran Bretaña» (CAERCAS, 1983e), y, finalmente, el general de brigada Basilio Lami Dozo, el tercer miembro de la Junta, prácticamente se rio de la insinuación: «¿Cómo podríamos pensar siquiera en un enfrentamiento militar con Gran Bretaña?» (CAERCAS, 1983e, p. 817).

12. Estos autores reconocen que el momento óptimo para la invasión habría sido después del 15 de mayo cuando el invierno hubiera impedido un despliegue y algunos barcos británicos hubieran quedado fuera de servicio (CAERCAS, 1983b, p. 761). Sin embargo, su teoría no explica el momento subóptimo de la invasión, lo que representa un gran desafío a su argumento. 
Si todos los miembros de la Junta sabían casi con certeza que el Reino Unido derrotaría a Argentina en la guerra ¿por qué se mantuvieron en curso de colisión, negando la realidad ante sus ojos? Es esta la cuestión que debemos desentrañar para comprender el drama de las Malvinas. En la siguiente sección desarrollamos una explicación alternativa que considera este punto. Nuestra explicación enfatiza el declive de Argentina y sus efectos psicológicos, explicando la aceptación de altísimo riesgo que caracterizó el proceso decisorio e impidió una solución racional y negociada. La historia que proponemos tiene contrafácticos propios, que hacemos explícitos desde el principio para facilitar el análisis y mostrar la mayor coherencia de nuestro argumento.

\section{UNA ARGENTINA EN DECLIVE}

De acuerdo con la teoría prospectiva, los líderes de los Estados en declive pueden adoptar estrategias militares costosas y arriesgadas y prolongarlas a pesar de su utilidad decreciente. Nuestro marco, ilustrado sucintamente en la Figura 2, puede explicar elegantemente el enigma de las Malvinas. En esta sección argumentamos que la arriesgada política exterior de Argentina fue el resultado de su largo declive y la pérdida de las Malvinas para Gran Bretaña (nunca normalizada) se convirtió en un importante punto de referencia. Este poderoso marco de pérdida influyó en la Junta Militar debido a un proceso decisorio aislado y llevó en última instancia a la guerra.

En nuestra narrativa, seguimos implícitamente un método de elaboración de secuencias (Mahoney et al., 2009) en el que el declive argentino es necesario para que los militares adopten un marco de pérdida, que a su vez es necesario para grandes inversiones en armas, un comportamiento arriesgado y, finalmente, la guerra. Este enfoque teórico de conjuntos puede ser visualizado con las condiciones necesarias como superconjuntos de sus implicaciones.

La nuestra es una explicación INUS, lo que quiere decir que las condiciones previas al resultado (cada uno de los eslabones de la cadena causal) son «insuficientes en sí mismas, pero componente(s) no-redundantes de una combinación de condiciones que es innecesaria pero suficiente para un resultado» (Mahoney y Barrenechea, 2017, p. 314). Este conjunto INUS explica un camino causal específico a la guerra y que estas condiciones son necesarias para ese camino causal específico.

Nuestro argumento central puede expresarse de la siguiente manera: mientras que el error de cálculo y la necesidad de incrementar el apoyo popular a la Junta no son condiciones necesarias ni suficientes para el estallido de las hostilidades, el declive argentino, sumado al predominio de un marco de pérdida, la acumulación de costos irrecuperables (o hundidos) producidos por un gasto militar excesivo y el comportamiento estratégico arriesgado que siguió, fueron todos eslabones necesarios de una cadena que llevaría a la guerra. Puesto de otro modo, la combinación de estos factores resultó en una combinación suficiente para la invasión. Aunque otras combinaciones también podrían haber conducido al mismo resultado, en las secciones siguientes demostramos que esta combinación en particular se ajusta mejor que ninguna otra a la evidencia.

La Figura 2 muestra la lógica de nuestro argumento aplicado específicamente al caso de las Malvinas y enumera las afirmaciones contrafactuales que estamos haciendo. La figura 


\section{FIGURA 2. EXPECTATIVAS PARA UN NUEVO ANÁLISIS CONTRAFÁCTICO}
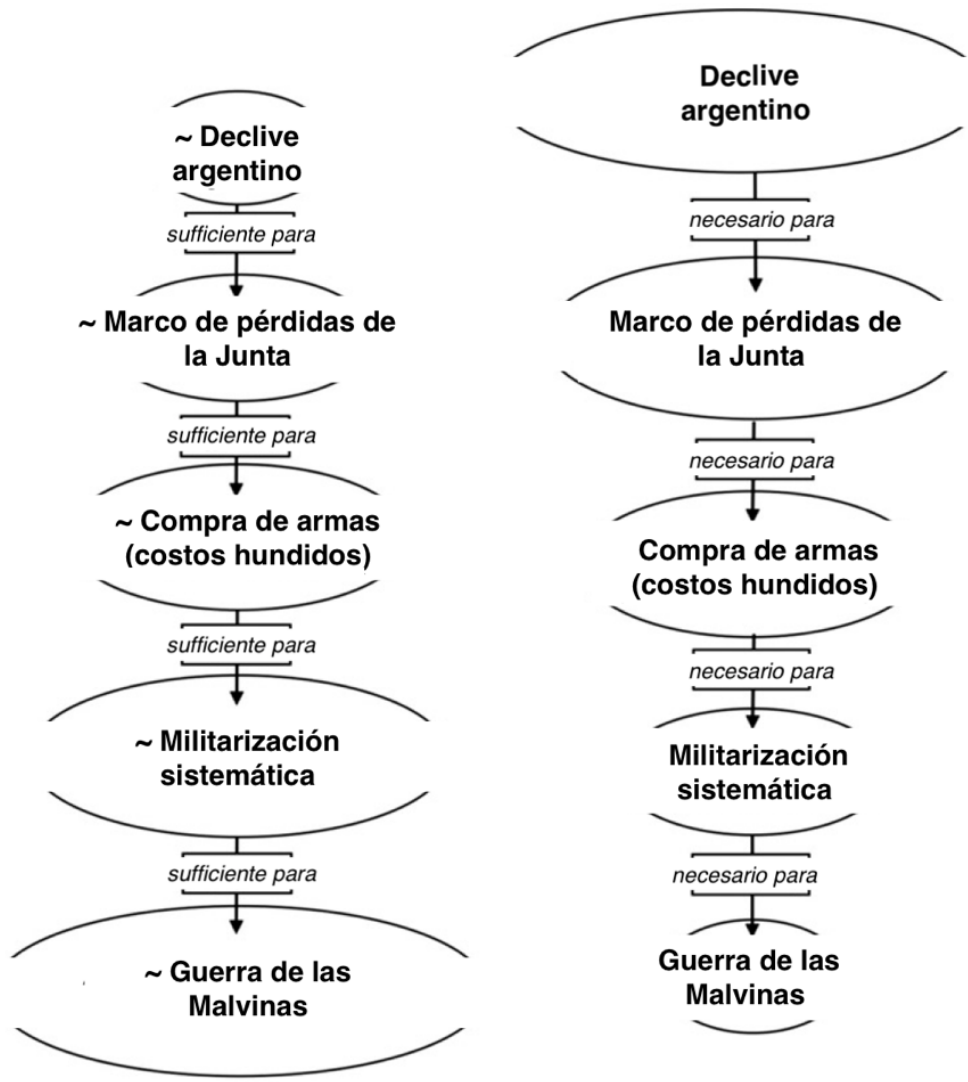

Fuente: Elaborada por los autores con base en Mahoney y Barrenechea (2017).

también aclara otra implicación de nuestro argumento. Cada vez que decimos que un factor es necesario para que ocurra otro, estamos implicando simultáneamente que la ausencia (denotada por $\sim$ ) del primero es suficiente para generar la ausencia del siguiente. Por ejemplo, el afirmar que el declive de Argentina fue necesario para la consolidación de un marco de pérdidas equivale a afirmar que, sin este declive, el tipo de pensamiento predicho por la teoría prospectiva no habría predominado. En análisis contrafáctico la necesidad de cada vínculo se evalúa de acuerdo con las realidades del caso (Levy, 2015, p. 379), a través de la creación de un «mundo posible, paralelo o alternativo» en el que solo lo antecedente no ocurrió, pero todas las demás características del caso se mantienen constantes. En las próximas secciones nos ocuparemos de mostrar de este modo no solo la presencia de los factores clave de nuestra historia, sino también estas relaciones de necesidad y suficiencia. Al hacerlo, demostramos 
que nuestra propia hipótesis no es vulnerable, al menos, al tipo de problemas que encontramos en las tesis de error de cálculo y de la guerra de distracción.

\section{CAMBIO DE PODER}

La causa de fondo del conflicto en las Malvinas/Falklands fue el declive relativo de Argentina frente a sus competidores en su región. Es un hecho bien conocido de que Argentina era una potencia en declive a mediados del siglo XX (Escudé, 1981). Como muestra la Figura 3 , países alguna vez comparables a Argentina, como Brasil y México ${ }^{13}$, ampliaron su brecha de capacidades materiales, mientras que vecinos más pequeños como Chile redujeron esta diferencia. En una lista clasificada de las economías más grandes del mundo, Argentina cayó de la posición 8 a la 22 de 1960 a 1980.

El fuerte declive de Argentina generó preocupación sobre su estatus y prestigio que se expresaron claramente en el pensamiento de la Junta. Una de las principales características de la política exterior del régimen militar fue «un nacionalismo expansivo que pretendía reordenar la posición de Argentina en el mundo y en el contexto latinoamericano» (DomínguezRuiz, 1983, p. 98; Lisinska, 2019). En su declaración ante la Comisión Rattenbach, Anaya (año) dice que la Junta creía que «Argentina recuperaría el liderazgo en América Latina al tener una dignidad que, durante años, por muchos años, no lo había hecho» (CAERCAS, 1983 e, p. 708). En este contexto, una serie de retrocesos relacionados con disputas territoriales activas se interpretaron como afrentas concretas a la posición regional argentina. En 1977, la reina Isabel II adjudicó tres islas en el canal Beagle a Chile en un laudo arbitral, que el gobierno argentino declaró nulo, pero hizo casi imposible la recuperación de las islas por medios legales. En 1979, el gobierno militar hizo concesiones a Brasil en el Acuerdo Tripartito de Corpus-Itaipú, que los intransigentes interpretaron como una capitulación del control sobre el flujo del río Paraná a un viejo enemigo. Los miltares argentinos también tenían grandes esperanzas de que el proceso de descolonización permitiría la reincorporación de las Malvinas, pero el proceso estaba llegando a un impasse global y las negociaciones con Gran Bretaña se estancaron durante la administración del Partido Conservador de Margaret Thatcher (figura 3).

\section{MARCO DE PÉRDIDA}

Habiendo sufrido un declive en relación con sus pares, así como pérdidas territoriales concretas, las élites argentinas no lograron renormalizar su punto de referencia. Tal como predice la teoría prospectiva, los militares argentinos, tomando decisiones en un contexto de pérdidas, evaluaron su situación actual sin basarse en el statu quo objetivo, sino en el statu quo ante. Este fenómeno ha llamado la atención de muchos científicos sociales argentinos antes que nosotros. De acuerdo con una narrativa del «poder desmembrado» o de la «Argentina

13. México está geográficamente distante de Argentina, pero es un competidor en los foros multilaterales, donde los dos países históricamente han disputado el liderazgo de Hispanoamérica. 

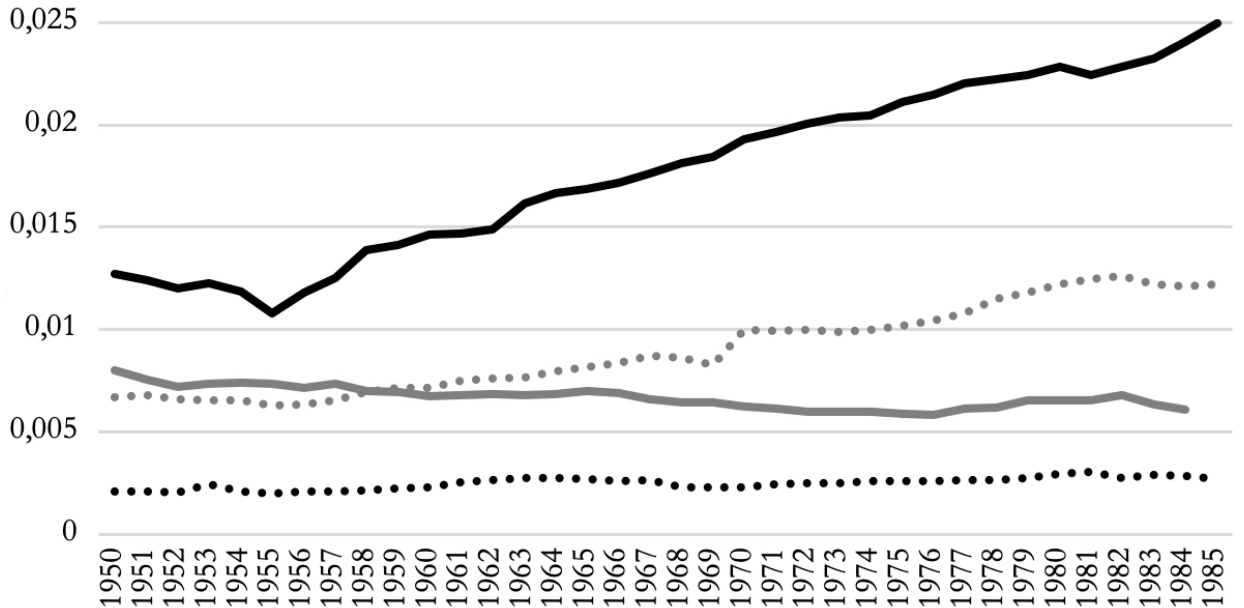

Argentina $\quad . . .$. Mexico

Brasil

Chile

Notas: El eje vertical representa el porcentaje de las capacidades materiales del mundo que corresponden a cada uno de estos países. Este Índice Compuesto de Capacidades Nacionales se basa en seis indicadores de poder internacional: consumo de energía, producción de hierro y acero, gasto militar, personal militar, población total y población urbana.

Fuente: Correlates of War. Composite Index of National Capabilities.

fantástica» que había sido predominante durante la década de 1960, a pesar de su enorme extensión territorial en el momento de su independencia, Argentina había sufrido un lento proceso de «desmembramiento» por la acción de Estados vecinos y poderes extrarregionales (Lacoste, 2003). Desde este punto de vista, Argentina habría sido una gran potencia si hubiera mantenido los territorios actuales de Perú, Bolivia, Paraguay, Uruguay y una gran parte de Chile que perteneció al Virreinato del Río de la Plata (1776-1814), cuya capital era Buenos Aires (Palermo, 2007).

Los sistemas de educación primaria y secundaria difundieron cada vez más los marcos sobre la «Argentina fantástica» y el «poder desmembrado» en las décadas que condujeron a la guerra de las Malvinas (Escudé, 1989). Durante la década de 1950, la escuela cartográfica adoptó esos conceptos definiendo a Argentina como nación en retroceso constante y a Chile como Estado expansionista (Lacoste, 2003). Esta visión fue consolidada a través del Atlas de Desarrollo Territorial de Argentina, apoyado por las principales instituciones académicas y científicas del país, y distribuido ampliamente a través de las escuelas del país. Su introducción declaró que el principal objetivo del trabajo era «resaltar los contornos del territorio que tenía el Virreinato del Río de la Plata en la época en que Argentina se independizó de España para 
servir como base para aplicar el documento trígono del uti possidetis (como poseías, así puedes poseer)» (Randle, 1981).

Estas pérdidas territoriales cobraron gran importancia en la mente de los líderes militares, los cuales las vincularon con la supervivencia del Estado. Un supuesto principal fue que los Estados vecinos siempre estaban al acecho, esperando una oportunidad para aprovecharse de Argentina (Kahlat, 2007; Marini, 1984; Fraga, 1979). Un exponente de este punto de vista argumentó que «Chile es un país que ha estado en la ley de expansión desde la era de la emancipación sudamericana; Argentina en la ley de la resistencia» (Marini, 1984). Otra voz representativa se quejó del «impulso expansivo de Chile a expensas de nuestro país» (Fraga, 1979, p. 124). Esto contribuyó a la opinión de que la pérdida de las islas del canal Beagle sería una más en una serie de pérdidas para Chile, lo que a su vez endureció la posición argentina.

La visión de las Malvinas como parte de este territorio «amputado» (Merke, 2018) resurge en el siglo XX después de muchas décadas de aquiescencia más allá del reclamo diplomático formal (Guber, 1999). Una figura clave en la transformación de las Malvinas en una causa popular fue Alfredo Palacios, un senador socialista que defendió la causa de la recuperación de la soberanía argentina en la década de 1930. Pero la idea de las Malvinas como una «pérdida territorial» pasó a ocupar un lugar central en la política solo en las décadas de 1960 y 1970 (Escudé, 2010). Fue entonces cuando los tomadores de decisiones argentinos comenzaron a creer que «Argentina estaba incompleta si las islas no eran recuperadas» (Palermo, 2007). Si bien se puede decir que esta visión cabía a todas las élites políticas (Escudé y Cisneros, 2000), el marco de pérdida o del «poder desmembrado» fue particularmente fuerte en las Fuerzas Armadas, y las islas Malvinas se convirtieron en un evidente punto focal para los militares.

Este argumento demuestra que no fue solo una «mentalidad militar» sobre el uso de la fuerza que condujo al conflicto (Weeks, 2014), sino un liderazgo militar profundamente afectado por un largo patrón de declive y el sentimiento de pérdida que lo acompañaba. Probablemente el eslabón más importante de la cadena de eventos que condujo a la invasión de las islas fue la consolidación de una facción agresiva del Ejército (Pion-Berlin, 1997) decidida a devolver a Argentina su anterior estatus internacional (Russell, 1987) y aislarla de otros actores dentro del gobierno.

En las entrevistas de Rattenbach, los tres miembros de la Junta mencionan que Argentina estaba en declive y bajo amenaza, y que debían tomarse medidas para restaurar su estatus. Es natural que un marco de pérdida llegara a predominar en los niveles más altos del Estado después del golpe militar de 1976 dado el aislamiento de la Junta de los mecanismos dentro del Estado que de otro modo podrían haber atenuado estos sesgos cognitivos. La insularidad y el secretismo en la toma de decisiones de la Junta es difícil de exagerar. Cuando la decisión de invasión se tomó en enero, no más de diez individuos, todos ellos oficiales militares, conocían estos planes. El número de individuos involucrados había aumentado solo a dieciséis el 16 de marzo, dos semanas antes del aterrizaje. El único civil involucrado fue el ministro de Relaciones Exteriores (Santibáñez, 2007). Debido al marco institucional flexible del Proceso de Reorganización Nacional (PRN), la Junta podía excluir a muchos ministerios civiles. El ministro de Defensa, por ejemplo, debería haber sido parte del Comité de las Fuerzas Armadas desde el inicio según la Ley de Defensa Nacional. No obstante, se lo excluyó. Cuando se le preguntó por esta anomalía, Galtieri respondió que el ministro de Defensa fue excluido precisamente «por su condición de civil y su entrenamiento particular», a lo que Rattenbach 
respondió con entusiasmo: «¿No habría sido útil la presencia de una mentalidad civil para tres mentes militares?» (CAERCAS, 1983e, p. 692).

\section{COSTOS IRRECUPERABLES}

Para que Argentina haya librado una guerra por las islas Malvinas, la Junta argentina debía tener suficientes tropas y armas para combatirla. En esta sección, señalamos la importancia de adquisiciones de defensa argentina significativas y los efectos psicológicos que acompañaron estas «inversiónes irrecuperables» o «costos hundidos». La teoría cognitiva espera que las inversiones realizadas en persecución de una política particular influyan en las decisiones futuras. Esto sugiere que las inversiones realizadas en la década de 1970 habrían entrado en el cálculo estratégico en escenarios como la crisis de Beagle y Malvinas, respectivamente, como costos irrecuperables en material que debía ser utilizado para su propia amortización (Rougier, 2015).

Debido al pensamiento estratégico derivado directamente del mencionado marco de pérdidas, Argentina modernizó rápidamente sus Fuerzas Armadas en la década de 1970, comprando dos submarinos de los Estados Unidos en 1974, cuatro destructores de Alemania en 1978 y dos más del Reino Unido en 1977 y 1981. El grueso de la Armada argentina en la época de la invasión estaba compuesto por un portaaviones, un crucero, siete destructores y cuatro submarinos (IISS, 1979; Arquilla y Moyano-Rasmussen, 2001); es razonable concluir que, si Argentina no hubiera comprado estos barcos, las esperanzas de una invasión exitosa habrían sido escasas ${ }^{14}$. El número de aviones de combate -una tecnología que demostró ser clave durante la guerra- también aumentó drásticamente durante la dictadura militar de 132 a 216. Los tanques de batalla también aumentaron de 120 a 185 (IISS, 1982).

Estas inversiones no produjeron solo aumentos cuantitativos, sino también una mejora cualitativa de la capacidad operativa combinada de las fuerzas. A mediados de la década de los 70, las Fuerzas Armadas argentinas eran el único ejército en América Latina que podría desplegar un grupo de combate naval con un portaaviones equipado con quince cazas A-4Q más ocho destructores de escolta, entre ellos un Type 42 de fabricación británica, el más avanzado en ese momento. Además, la Armada contaba con dos submarinos alemanes de la clase Type 209, que fueron máquinas de última generación. En comparación, Chile no tenía un portaaviones y el brasileño Minas Gerais solo podía operar con helicópteros. A estas capacidades se sumaría, a principios de la década de 1980, el dúo Super Éterndart/Exocet que le dio a la Aviación Naval argentina un gran poder ofensivo. La Fuerza Aérea, por su parte, tuvo aviones de combate de última generación como el Mirage III, el Mirage V Dagger y el avión A-4C. Ni la fuerza brasileña ni la chilena tenían aviones en tal cantidad y calidad (IISS, 1982). Asimismo, el Ejército había alcanzado un alto nivel de autosuficiencia en la producción de armas debido a la implementación del Plan Europa, que impulsó la producción nacional de

14. Por ejemplo, toda la tecnología de la Armada argentina hubiera sido comparable a la del ARA General Belgrano, el barco argentino sin tecnología antisubmarina que fue fácil y vergonzosamente hundido fuera de la zona de exclusión durante el primer día de combate. 
FIGURA 4. GASTO MILITAR EN ARGENTINA 1950-85

5000000

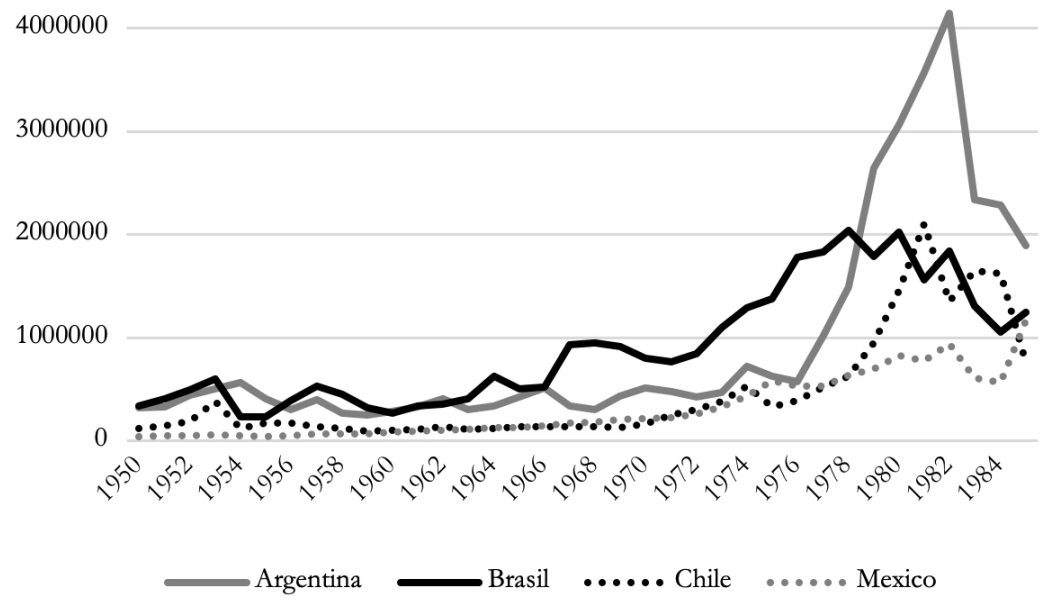

Fuente: Correlates of War. Composite Index of National Capabilities.

tanques, artillería pesada, morteros, equipos de comunicaciones, municiones, rifles y ametralladoras, entre otros artículos (Fraga, 1988).

La Figura 4 muestra las respectivas evoluciones de los presupuestos de defensa de Argentina y los tres países latinoamericanos en la Figura 3. Una primera línea discontinua vertical marca el comienzo del PRN y una segunda marca la guerra de las Malvinas/Falkland. La figura muestra un crecimiento exponencial en gasto militar, «transformando rápidamente lo improbable en lo inevitable» (Tetlock y Belkin, 1996, p. 20), lo que refuerza nuestro contrafactual. En otras palabras, si Argentina hubiera mantenido su nivel anterior de gastos militares, una adquisición de armas posteriores y un comportamiento militarista imprudente habrían sido «improbables». Es más, el mayor aumento relativo en los gastos tuvo lugar claramente mucho antes de la guerra, entre 1976 y 1979.

Diferentes documentos y declaraciones de oficiales militares de alto rango revelan una percepción generalizada de que Argentina se había convertido temporalmente en una potencia militar ${ }^{15}$. El jefe de Estado Mayor del Ejército declaró: «El Ejército ha alcanzado una madurez doctrinal y orgánica que lo coloca al nivel de los más avanzados del mundo» (Fraga, 1988, p. 61). En las declaraciones a la Comisión Rattenbach, está claro que Lami Dozo (CAERCAS, 1983e, p. 810 y Galtieri (CAERCAS, 1983e, p. 690) eran conscientes de la enorme inversión que el país hacía en esas tecnologías y sintieron la necesidad de utilizarlas antes

15. La ventana de oportunidad para traducir su superioridad militar en ganancias territoriales se estaba cerrando porque Argentina no podía mantener los gastos militares tan altos como el 4 por ciento de su producto interno bruto indefinidamente. 
de que se volvieran obsoletas. Anaya pensó: «El castigo que podríamos infligir (en la flota británica) era muy grande... y que en ese momento no podía ser resistido por Gran Bretaña ${ }^{16}$. La idea es que dada la enorme inversión que Argentina había hecho en la década anterior, es decir, dados los costos irrecuperables, los militares se vieron obligados a aprovechar la oportunidad, lo cual era «bien conocido a nivel del mando operacional naval» (CAERCAS, 1983e).

\section{ACEPTACIÓN DE RIESGO}

El declive relativo de Argentina frente a sus competidores y las pérdidas territoriales, más la sensación de pérdida que lo acompañaba por el declive inculcado en la Junta Militar, contribuyeron al tipo de planificación ofensiva e inversiones necesarias que eran necesarias para la militarización de varios frentes.

La Figura 5 muestra el aumento en el número de disputas interestatales militarizadas (MIDs, por su nombre en inglés) que involucran a Argentina durante el período bajo análisis (Jones et al., 1996). Esta figura ilustra cómo las Fuerzas Armadas argentinas fueron especialmente propensas a producir episodios de militarización antes de la guerra de las Malvinas, con una frecuencia cada vez mayor desde mediados de la década de 1950. Ejemplos prominentes incluyen la improbable militarización de la disputa del Río de la Plata con Uruguay ${ }^{17}$ y el escalamiento con Brasil en torno a la disputa sobre la construcción de la represa hidroeléctrica de Itaipú (Darnton, 2012). Como hemos visto, Chile y Gran Bretaña fueron frecuentemente el blanco de estas políticas a fines de la década de 1970.

Varios aspectos de estas MIDs que están en línea con nuestro argumento, permanecen ocultos en la Figura 5. Por ejemplo, el 87 por ciento de las MIDs posteriores a 1945 estuvieron relacionadas con reclamos territoriales y el 78 por ciento tuvieron a Argentina como instigador. Además, de acuerdo con la escala de severidad de Correlates of War, las MIDs en la década que precedió a la guerra fueron dos veces más severas que el promedio de las MIDs del siglo XX. Al observar la evaluación de riesgos de los planificadores de estrategias a lo largo de la década de 1970, podemos distinguir cómo los marcos de pérdidas y los costos irrecuperables afectaron cada vez más a los tomadores de decisiones a finales de la década. La Operación Soberanía es un ejemplo de ello ${ }^{18}$, pero también es el caso de varios planes que, afortunadamente, nunca se llevaron a cabo ${ }^{19}$.

16. Ibid., p. 765 .

17. El incidente más notable fue la ocupación de la isla Timoteo Domínguez por fuerzas argentinas el 13 enero de 1969. Este fue el episodio más grave de militarización entre estos dos países en más de un siglo (Escudé y Cisneros, 2000, p. 89).

18. Los planes de invasión incluían no solo la ocupación de las islas, sino una ofensiva generalizada sobre el territorio de Chile que supuso una ocupación completa en el transcurso de unos días. Afortunadamente, el movimiento de la flota fue suspendida a veinte millas náuticas de la costa de Chile debido a una fuerte tormenta, y el progreso de las tropas se detuvo después de que muchos pelotones argentinos hubieran entrado en territorio chileno (Passarelli, 1998).

19. «Mostrando la mentalidad del régimen militar argentino en la década de 1970, como otro ejemplo, estaba el 'Plan Rosario' según el cual Argentina atacaría las Malvinas y luego giraría para asentar el Canal Beagle por la fuerza. La secuencia, según el plan, también podría revertirse» (Holsti, 1996, p. 160). 


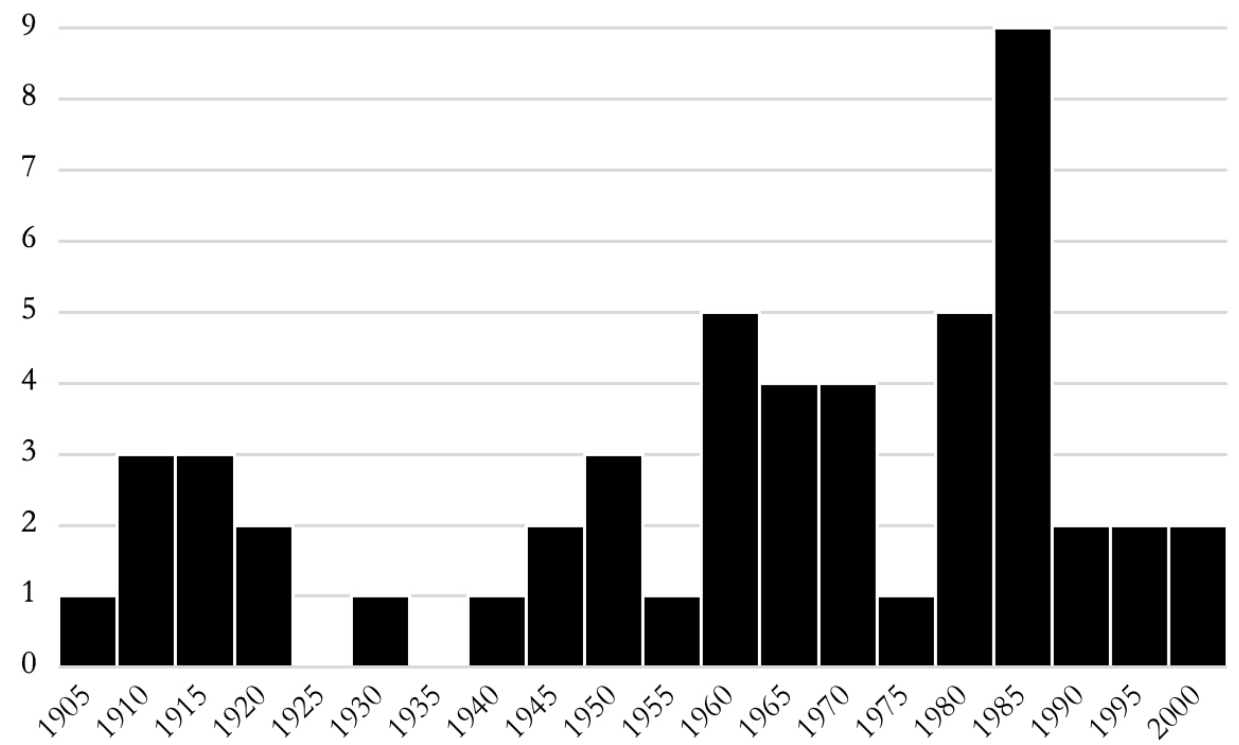

Fuente: Correlates of War. Militarized Interstate Disputes v4.3.

Declaraciones de miembros de la élite militar argentina indican que la lógica de la aceptación del riesgo se naturalizó. En particular, dado que se percibía un éxito relativo en las islas Thule, la Armada planeaba tomar medidas similares en otros territorios ${ }^{20}$. El comandante de la flota argentina, el almirante Lombardo, declaró: «En 1977 hubo una tibia reacción inglesa (al establecimiento de una base en las islas Thule). Y desde entonces se estableció ese destacamento, lo que significó un buen aporte a nuestros derechos en las islas y en el sector antártico. Entonces propuse algo similar en las Georgias... un establecimiento científico, para luego ver si podríamos progresar en darle el carácter de ocupación militar o política» (CAERCAS, 1983b, p. 63).

Esto conecta muy bien con el detonante inmediato de la guerra: el incidente del sur de la isla de Georgia de marzo de 1982, también conocido como el Incidente Davidoff. En este

20. Como señala David Mares, los argentinos no solo tenían el precedente de las islas Thule, sino que también estudiaron episodios anteriores de diplomacia coercitiva como la Crisis de Suez de 1956, la ocupación india de la colonia portuguesa de Goa en 1961 y la declaración unilateral de independencia de Rhodesia en 1965. La interpretación de estos hechos fue que la comunidad internacional condenó en un principio la acción armada, pero luego aceptaron sus consecuencias como hechos consumados (Mares, 2001, p. 156). 
episodio, un grupo de comerciantes argentinos de chatarra izó una bandera en la isla, provocando una crisis diplomática y el escalamiento bilateral que finalmente llevó a la decisión de tomar las Malvinas el 2 de abril. Como dijo el contralmirante Alberto Vigo, miembro del Estado Mayor, a la Comisión Rattenbach: «Las Malvinas fueron ocupadas como consecuencia de una serie de incidentes, cada vez más graves, que culminaron en la decisión de tomar las islas sin pensar si la oportunidad era buena o mala» (CAERCAS, 1983c, p. 277). La Figura 6 proporciona un sucinto «mapa de eventos» (Waldner, 2015), una cadena causal de casos específicos que resumen la narrativa presentada en esta sección de una manera fácilmente comparable con los mecanismos causales de la Figura 1, con condiciones necesarias, o causas antecedentes en la cadena causal, que toman lugar en la secuencia predicha.

\section{FIGURA 6. MAPA DE EVENTOS: CONDICIONES NECESARIAS QUE LLEVARON A LA GUERRA}

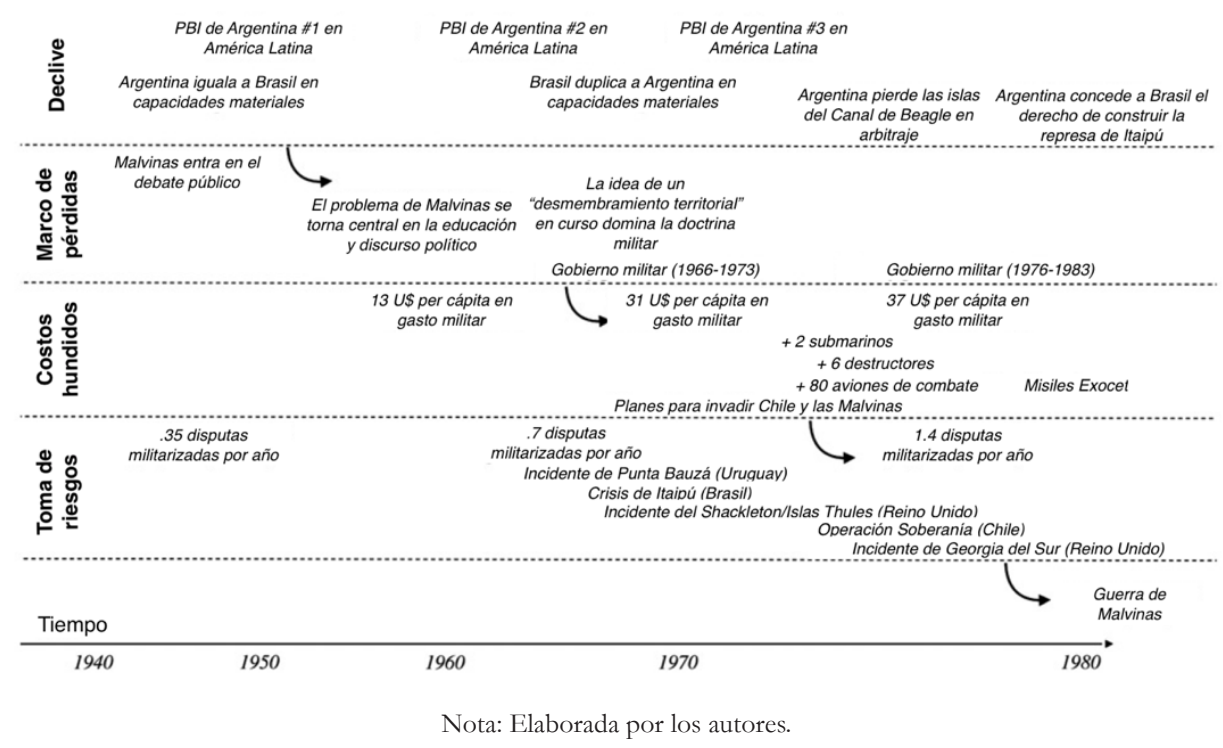

\section{CONCLUSIONES}

En este artículo utilizamos la evidencia recientemente desclasificada de la Comisión Rattenbach (la investigación más completa sobre las causas y la dirección de la guerra de las Malvinas) para reinterpretar los orígenes de la guerra. Al hacerlo, brindamos dos contribuciones importantes. Primero, mostramos que las tesis de la guerra de distracción y el error de cálculo, que han sido parte de una narrativa dominante sobre la guerra, son fundamentalmente irreconciliables con la nueva evidencia. Los militares argentinos no consideraron la política 
interna en sus evaluaciones estratégicas y previeron correctamente $-\mathrm{y}$ con impresionante detalle- una respuesta británica a la invasión. Nuestra falsificación de la tesis de la guerra de distracción debe considerarse como una contribución particularmente importante ya que la guerra de las Malvinas es a menudo un ejemplo clave en esta literatura.

En segundo lugar, desarrollamos nuestra propia explicación basada en la teoría prospectiva. El declive relativo de Argentina frente a sus competidores, sumado a pérdidas territoriales concretas, provocaron que una Junta aislada e influenciada por un marco de pérdida participara en una larga serie de ofensivas terminando en la guerra de las Malvinas. El análisis contrafactual de teoría de conjuntos que llevamos a cabo demuestra que nuestra explicación es totalmente coherente con los acontecimientos que llevaron a la guerra y la interpretación de los actores clave entrevistados por Rattenbach.

Nuestro argumento puede ser de utilidad para futuras investigaciones. En primer lugar, nuestra explicación para el comportamiento arriesgado de Estados en declive es una vía digna de seguir siendo explorada. Segundo, nuestro trabajo contribuye a la investigación de las condiciones bajo las cuales ciertas teorías psicológicas o emocionales de la toma de decisiones operan sobre el comportamiento del Estado. Este artículo ha demostrado que aspectos clave de la teoría prospectiva (específicamente la rigidez de los puntos de referencia entre aquellos que han incurrido en pérdidas) pueden aplicarse fructíferamente al estudio de las RRII.

\section{REFERENCIAS}

Abramson, S. y Carter, D. (2016). The Historical Origins of Territorial Disputes. American Political Science Revisión, 110(4), 675-698.

Arquilla, J. y Moyano Rasmussen, M. (2001). The Origins of the South Atlantic War. Journal of Latin American Studies, 33(4), 750-754.

Bueno de Mesquita, B. (1981). Risk, Power Distributions, and the Likelihood of War. International Studies Quarterly, 25(4), 541-568.

CAERCAS (1983a). Informe Final de la Comisión de Análisis y Evaluación de Responsabilidades en el Conflicto del Atlántico Sur, disponible en línea en: https://www.casarosada.gob.ar/pdf/InformeRattenbach/01InformeFinal.pdf

CAERCAS (1983b). Declaraciones a la Comisión de Análisis y Evaluación de Responsabilidades en el Conflicto del Atlántico Sur, Tomo 1, disponible en línea en: https://www.casarosada.gob.ar/pdf/ InformeRattenbach/12-Declaraciones-Tomo1.pdf

CAERCAS (1983c). Declaraciones a la Comisión de Análisis y Evaluación de Responsabilidades en el Conflicto del Atlántico Sur, Tomo 2, disponible en línea en: https://www.casarosada.gob.ar/pdf/ InformeRattenbach/13-Declaraciones-Tomo2.pdf

CAERCAS (1983d). Declaraciones a la Comisión de Análisis y Evaluación de Responsabilidades en el Conflicto del Atlántico Sur, Tomo 3, disponible en línea en: https://www.casarosada.gob.ar/pdf/ InformeRattenbach/14-Declaraciones-Tomo3.pdf

CAERCAS (1983e). Declaraciones a la Comisión de Análisis y Evaluación de Responsabilidades en el Conflicto del Atlántico Sur, Tomo 4, disponible en línea en: https://www.casarosada.gob.ar/informacion/ archivo/25773-informe-rattenbach 
CAERCAS (1983e). Declaraciones a la Comisión de Análisis y Evaluación de Responsabilidades en el Conflicto del Atlántico Sur, Tomo 5, disponible en línea en: https://www.casarosada.gob.ar/pdf/ InformeRattenbach/16-Declaraciones-Tomo5.pdf

Camilión, O. (1999). Memorias Politicas: de Frondizi a Menem. Buenos Aires: Planeta.

Copeland, D. (2000). The Origins of Major War. Ithaca, NY: Cornell University Press.

Darnton, C. (2012). Un comienzo en falso en el camino hacia el Mercosur: reinterpretación del fracaso del acercamiento entre Argentina y Brasil, 1972. Revista Latinoamericana de Investigaciones, 47(2), $120-141$.

DEMIL (1982) Directiva de estrategia militar 1/82, disponible en línea en: https://drive.google.com/ drive/folders/0Bylq1Dv6DaxpUFB0YzRrcW1UMTJNTmV3TjF4YVFfdw? resourcekey=0-dkA 55cQUC5LulB-tLSd0jg

Domínguez Ruiz, R. (1983). Las relaciones Argentina-Estados Unidos: 1976-1980. Tesis doctoral. Universidad Nacional Autónoma de México.

Escudé, C. (1981). El eclipse argentino: el factor internacional en el declive de Argentina después de la Segunda Guerra Mundial. Tesis de doctorado. Universidad de Yale.

Escudé, C. (1989). Contenido nacionalista de la enseñanza de la geografía en la República Argentina 1879-1986. En Atilio Boron y Julio Faúndez (Eds.), Malvinas hoy: herencia de un conflicto. Buenos Aires: Puntosur.

Escudé, C. (1994). La falacia antropomórfica en el discurso de las relaciones internacionales. Documento de trabajo 94-06. Centro Weatherhead para Asuntos Internacionales, Universidad de Harvard, 1-20.

Escudé, C. (2010). El trasfondo cultural de la invasión argentina de las Malvinas: contenido nacionalista de la enseñanza de la geografía 1879-1986. Boletín del Centro Naval, 827, 169.

Escudé, C. y Cisneros, A. (2000). Historia general de las relaciones exteriores de la República Argentina, vol. 13. Buenos Aires: Grupo Editor Latinoamericano.

Fearon, J. (1991). Contefactuals and Hypothesis Testing in Political Science. World Politics, 43(2), 169-195.

Fraga, J. (1979). Argentina y los principios de la geopolítica. Estrategia, 58(1), 34-54.

Fraga, R. (1988). Ejército: del escarnio al poder (1973-1976). Buenos Aires: Planeta.

García Holgado, B. y Taccone, N. (2018). Diseño institucional e inestabilidad presidencial en autoritarismos: el Proceso de Reorganización Nacional en la Argentina (1976-1983). Desarrollo Económico, 58(224), 1-29.

Gibran, D. (1998). The Falklands War: Great Britain Versus the Past in the South Atlantic. Jefferson: Macfarland.

Gilpin, R. (1981). War and Change in International Politics. Cambridge: Cambridge University Press.

Glaser, C. (2010). Rational Theory of International Politics. Princeton: Princeton University Press.

Goddard, S. (2018). When Right Makes Might: Rising Powers and World Order. Ithaca: Cornell University Press.

Goertz, G. y Levy, J. (2007). Explaining War and Peace. London: Routledge.

Graham, A. (2017). Destined to War. Boston: Houghton Mifflin Harcourt.

Guber, R. (1999). Alfredo Lorenzo Palacios: honor y dignidad en la nacionalización de la causa Malvinas. Revista de Ciencias Sociales, 10, 83-116.

Hastings, M. y Jenkins, S. (1984). The Battle for the Falklands. New York: Palgrave Macmillan.

Holsti, K. (1996). The State, War, and the State of War. Nueva York: Cambridge University Press.

IISS (1979). International Institute for Strategic Studies: The Military Balance 1979-1980. London: Instituto Internacional de Estudios Estratégicos.

Itzkowitz, J. (2018). Rising Titanes, Falling Giants. Ithaca: Cornell University Press.

Jervis, R. (1992). Political Implications of Loss Aversion. Political Psicology, 13(2), 187-204. 
Jervis, R. (2010). Why Intelligence Fails? Ithaca, NY: Cornell University Press.

Jervis, R. (2017). Perception and Misperception in International Politics. Princeton: Princeton University Press. Jones, D., Bremer, S. y Singer, J. D. (1996). Militarized Disputes, 1816-1992: Rationale, Coding Rules and Empirical Patterns. Conflict Management and Peace Science, 15(2), 163-213.

Kahneman, D. y Tversky, A. (1979). Prospect Theory: An Analysis of Decision under Risk. Econometrica, 47, 263-291.

Kinney, D. (1989). National Interest, National Honor: The Diplomacy of the Falkland Crisis. New York: Praeger.

Kirshner, J. (2000). Rationalist Explanations of War? Security Studies, 10(1), 143-150.

Lacoste, P. (2003). La imagen del otro en las relaciones de la Argentina y Chile (1534-2000). Santiago: Fondo de Cultura Económica.

Lebow, R. (1983). Miscalculation in the South Atlantic: The Origins of the Falklands War. Journal of Strategic Studies, 6(1), 5-35.

Lebow, R. (2000). What is so Different About a Counterfactual. World Politics, 52(4), 550-585.

Levy, J. (1987). Declining Power and the Preventive Motivation for War. World Politics, 40(1), 82-107.

Levy, J. (1997). Prospect Theory, Rational Choice, and International Relations. International Studies Quarterly, 41(1), 87-112.

Levy, J. (2008). Counterfactuals and Case Studies. En Janet M. Box-Steffensmeier, Henry E. Brady y David Collier (Eds.), Oxford Handbook of Political Metodology. New York: Oxford University Press.

Levy, J. (2015). Counterfactuals, Causal Inference, and Historical Analysis. Security Studies, 24(3), 365-387.

Levy, J. y Vakili, L. (1992). Diversionary Action by Authoritarian Regimes: Argentina in the Falklands/ Malvinas Case. En Manus I. Midlarsky (Ed.), The Internationalization of Communal Strife. London: Routledge.

Lisinska, M. (2019). Argentine Foreign Policy during the Military Dictatorship 1976-1983. London: Palgrave Macmillan.

Luzuriaga, A. (2013). La inteligencia estratégica naval en la Guerra de Malvinas: un éxito poco conocido. Boletín del Centro Naval, 835, 71-78.

MacDonald, P. (2003). Useful Fiction or Miracle Maker: The Competing Epistemological Foundations of Rational Choice Theory. American Political Science Review, 47(4): 551-565.

MacDonald, P. y Parent, J. (2018). Twilight of Giants. Ithaca: Cornell University Press.

Mahoney, J. (2015). Process Tracing and Historical Explanation. Security Studies, 24(2), 199-214.

Mahoney, J., Kimball, E. y Koivu, K. (2009). The Logic of Historical Explanation in Social Sciences. Comparative Political Studies, 42(1), 114-146.

Mahoney, J. y Barrenechea, R. (2017). The Logic of Counterfactual Analysis in Case-Study Explanation. British Journal of Sociology, 70(1), 314.

Mares, D. (2001). Violent Peace. New York: Columbia University Press.

Marini, C. J. (1984). La crisis en el Cono Sur. Buenos Aires: Pleamar.

McDermott, R. (1998). Risk-Taking in International Politics. Ann Arbor: Michigan University Press.

Merke, F. (2018). The Malvinas Conundrum. British Politics Review, 15(1), 1-27.

Middlebrook, M. (1987). Task Force: The Falklands War, 1982. London: Penguin.

Moneta, C. (1984). The Malvinas Conflict. En Heraldo Muñoz y Joseph S. Tulchin (Eds.), Latin American Nations in World Politics. Boulder: Westview Press.

Novaro, M. (2010). Historia de la Argentina 1955-2010. Buenos Aires: Siglo XXI.

Oakes, A. (2006). Diversionary War and Argentina's Invasion of the Falkland Islands. Security Studies, 15(3), 411-445.

Onea, T. (2014). Between Dominance and Decline. Review of International Studies, 40(1), 125-152. 
Organski, A. y Kugler, J. (1980). The War Ledger. Chicago: University of Chicago Press.

Palermo, V. (2007). Sal en las heridas: Las Malvinas en la cultura argentina contemporánea. Buenos Aires: Sudamericana.

Passarelli, B. (1998). El delirio armado: Argentina-Chile, la guerra que evitó el Papa. Buenos Aires: Editorial Sudamericana.

Pion-Berlin, D. (1997). Through Corridors of Power: Institutions and Civil-Military Relations in Argentina. Philadelphia: Pennsylvania University Press.

Randle, P. (1981). Atlas del desarrollo territorial de la República Argentina. Buenos Aires: Oikos.

Rosato, S. (2003). The Flawed Logic of Democratic Peace Theory. American Political Science Review, 97(4), $580-601$.

Rougier, M. (2015). El Complejo Militar-Industrial. En Marcelo Rougier y Andrés M. Regalsky (Eds.), Los derroteros del estado empresario en la Argentina del siglo XX. Buenos Aires: Eduntref.

Russell, R. (1987). Las relaciones Argentina-Estados Unidos: del «alineamiento heterodoxo» a la «recomposición madura». En Monica Hirst (ed.), Continuidad y cambio en las Relaciones América Latinal Estados Unidos (pp. 24-45). Buenos Aires: Grupo Editor Latinoamericano.

Santibáñez, F. (2007). La efectividad de los gobiernos militares durante la guerra: el caso de Argentina en las Malvinas. Fuerzas Armadas y Sociedad, 33(4), 612-637.

Taliaferro, J. (2004). Balance of Risk. Ithaca: Cornell University Press.

Tetlock, P. y Belkin, A. (1996). Counterfactual Thought Experiments in World Politics. Princeton: Princeton University Press.

Thompson, W. (2014). Status Conflict, Hierarchies, and Interpretation Dilemmas. En T. V. Paul, Deborah Welch Larson y William C. Wohlforth (Eds.), Status in World Politics. Cambridge: Cambridge University Press.

Villar Gertner, A. (2016). Autonomy and Negotiation in Foreign Policy. London: Palgrave Macmillan.

Waldner, D. (2015). Process Tracing and Qualitative Causal Inference. Security Studies, 24(2), 239-250.

Weeks, J. (2014). Dictators at W ar and Peace. Ithaca, NY: Cornell University Press.

Wolf, R. (2011). Respect and Disrespect in International Politics. International Theory, 3(1), 105-142. 
